\title{
Plasma etch properties of organic BARCs
}

\author{
Runhui Huang, Michael Weigand \\ Brewer Science, Inc., 2401 Brewer Drive, Rolla, MO 65401, USA
}

\begin{abstract}
Plasma etching is an integral part of semiconductor integrated circuit (IC) processing and is widely used to produce high-resolution patterns and to remove sacrificial layers. Bottom anti-reflective coatings (BARCs) under the resist absorb light to minimize reflectivity during lithography and are typically opened during pattern transfer using plasma etching. High etch selectivity is required in the BARC opening process to minimize resist loss to allow further substrate etching. Because the plasma etch process combines physical bombardment and chemical reaction, the factors affecting etch rate and selectivity are complex. The results are related to etch conditions and the chemical nature of polymer.

This paper addresses plasma etch properties as they relate to polymer type and etch gas composition. Polyacrylate, polyester, and polymers containing nitrogen and halogens have been investigated. The research was carried out by a series of designs of experiments (DOEs), which varied the flow rate of $\mathrm{Ar}, \mathrm{CF}_{4}$, and $\mathrm{O}_{2}$ in plasma gas. The selectivity of BARC to resist depends not only on the carbon content but also on the different ways polymer compositions and structures respond to an oxidizing gas, a reducing gas, and plasma bombardment. Based on a polymer decomposition mechanism, we discuss what could happen physically and chemically during the polymer's exposure to the high-energy reactive plasmas. We also modified the Ohnishi parameter for the polymers containing nitrogen and halogen using our polymer decomposition theory. The contribution of nitrogen and halogen in the etch equation can be positive or negative depending on the chemical properties of the plasma.
\end{abstract}

\section{INTRODUCTION}

Plasma etching is an integral part of semiconductor integrated circuit (IC) processing and is widely used for a variety of applications such as high-resolution pattern definition, selective processing over topography, planarization, and sacrificial layers stripping. A plasma process that is used to transfer lithographically defined patterns into thin layers must satisfy constraints that include dimensional control, etch selectivity to mask, and the nature of the underlying surface or layer [1,2]. The behaviors of most inorganic materials used in semiconductor processing, such as silicon, polysilicon, silicon nitride, and silicon dioxide, have been well characterized. Their etching directionality and etching selectivity can be controlled by etch gas composition and other plasma conditions.

The major organic materials involved in the plasma etch process are the photoresist and the bottom anti-reflective coating (BARC). The resist forms a high-resolution pattern when exposed under an ultraviolet light source. The BARC under the resist absorbs the light that travels through the resist layer to minimize reflectivity and enhance critical dimension (CD) and uniformity. During the pattern transfer, in the BARC opening process, high etch selectivity of resist and BARC is required to minimize resist loss to allow further substrate etching. Unlike inorganic materials, the compositions and structures of the polymers are very complex. A few mathematical models that predict the relationship of polymer chemical structure and etch rate have been established, such as the Ohnishi parameter [3], the ring parameter [4], and the bond contribution model [5]. The ring parameter is a rough model limited by the fact that it works for only polymers containing aromatic rings. The bond contribution model is concerned with chemical structures by giving single bond and double bond different parameters in the equation. However, bond breaking is a part of plasma etch, to move material into gas phase, sputter and chemical reaction are also important.

The Ohnishi parameter, the most popular model, states that etch rate is proportional to the effective carbon content in the polymer as a function of $N_{T} /\left(N_{C}-N_{O}\right)$, where $N_{T}$ is the total number of atoms, $N_{C}$ is the number of carbon atoms, and $N_{O}$ is the number of oxygen atoms. The Ohnishi parameter generally describes the basic trend of polymer etching, and most polymers follow the trend well. Later researchers did many modifications based on the Ohnishi model and tried to make 
the equation more accurate, for example, by combining the carbon and oxygen content with the ring parameter [6] and by introducing the number of fluorine atoms, $N_{F}$, in the Ohnishi equation for the polymers containing fluorine $[7,8,9]$. These modifications fit experimental data better mathematically, but they all lack an explanation of physical meaning.

Also, many researchers focused on how a polymer decomposes under plasma attack. As we know, plasma etching is a process of physical bombardment and chemical reaction. A surface is exposed to fluxes of atoms, molecules, ions, electrons, and photons, which break the chemical bonds and react with elements at the interface of the gas and the solid [2]. In the gas phase, the energy of particles, gas concentration, gas residence time, and the rate of sweeping away active species are all factors that determine the efficiency of the bombardment and reaction. For the solid, chemical composition and bonding type both affect the etch process. Many papers have presented studies of polymer surface change after plasma etching using Fourier transform infrared spectroscopy (FTIR), X-ray photoelectron spectroscopy (XPS), real-time mass spectrometry (MS), and secondary ion mass spectrometry (SIMS) $[10,11,12]$. However, because plasma etching is a very aggressive and fast process, it is difficult to catch the information using normal analysis instruments.

For this paper, we studied several types of polymers and their responses to different etch gases. A polymer decomposition mechanism for the plasma etch process has been developed which clearly connects the polymer structure and the etch results. Based on this theory, we modified the Ohnishi parameter as well.

\section{EXPERIMENT}

The polymers tested in this study were synthesized at Brewer Science, Inc. The BARC formulations were made by blending polymers, crosslinkers, catalysts, and other additives. All materials are protected by patents or are covered in previous technical publications. BARC1 is a polyacrylate matrial; BARC2 is an isocyanurate material; BARC3 is polyester with isocyanurate in main chain. The formulations were coated on silicon wafers and baked at $205^{\circ} \mathrm{C}$ to cure the films. The resist used in this research is a commercial available polyacrylate material. The thicknesses were measured on Variable-angle Spectroscopic Ellipsometer (VASE), model M2000, made by J.A. Woollam Co.

The etcher used in this study was an Oxford Plasmalab ${ }^{\circledR} 80$ Plus reactive ion etching (RIE) system. All experiments described here were carried out in discharges maintained at a source power of 200 watts and a pressure of 50 mtorr. A constant gas flow rate of $50 \mathrm{sccm}$ for $\mathrm{CF}_{4}, \mathrm{O}_{2}$, Ar, or mixtures thereof was injected in the discharge region. Wafers were mounted on the chuck, etched for 30-60 seconds. The cooling system kept the wafer temperature at $25^{\circ} \mathrm{C}$.

\section{RESULTS AND DISCUSSION}

\subsection{Etch gas composition DOE}

$\mathrm{C}_{\mathrm{x}} \mathrm{F}_{\mathrm{y}}, \mathrm{O}_{2}$, and $\mathrm{Ar}$ are three gases that typically are used for the BARC opening process. $\mathrm{O}_{2}$ is used for combusting carbon, $\mathrm{C}_{\mathrm{x}} \mathrm{F}_{\mathrm{y}}$ is used for increasing selectivity of BARC to resist, and $\mathrm{Ar}$ is used for promoting the sputtering component. In this study, we chose $\mathrm{CF}_{4}, \mathrm{O}_{2}$, and $\mathrm{Ar}$ as etch gases. A series of experiments were designed in mixture model with a constant total gas flow rate and variable gas ratios. The result was analyzed in Design Expert 7 software to find the behavior of different polymers in plasma etching.

\subsubsection{Polyacrylate}

An ArF resist was tested first as a standard to determine etch selectivity, and the resulting contour graph of etch rate is shown in Figure 1. This resist is an acrylate polymer, and its etch rate increased with increasing $\mathrm{O}_{2}$ content in the etch recipe, which means burning of a carbon compound is the major step that dominates the etch process. The other two gases had a minimal effect on etch rate.

BARC1 tested in this experiment is also an acrylate polymer. Figure 2 shows the etch rate of BARC1 and its etch selectivity to the resist. The etch rate of BARC1 in Figure 2 a followed the same trend as the resist did because they are 
same type of polymer. The more $\mathrm{O}_{2}$ in the etch recipe, the faster the etch rate. The selectivity of BARC1 to the resist in Figure $2 \mathrm{~b}$ is not very high; in this case, the highest selectivity is only 1.15 .

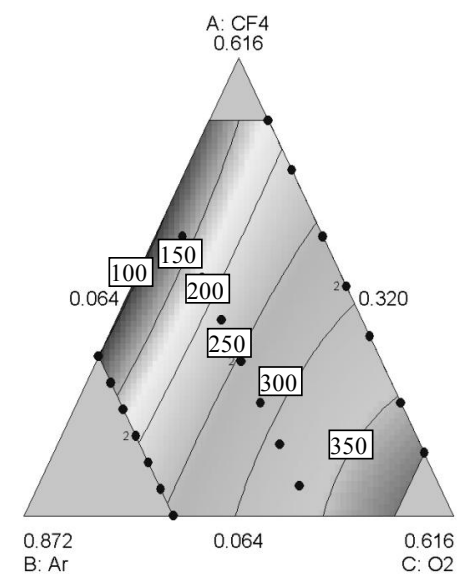

Figure 1. The etch rate $(\mathrm{nm} / \mathrm{min})$ of an ArF resist in the mixing gases plasma etch

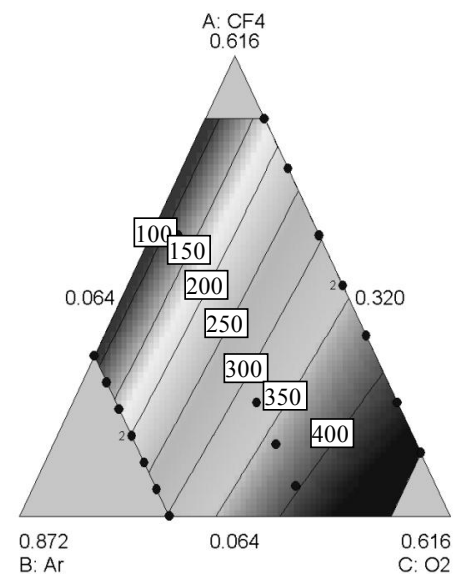

a. Etch rate $(\mathrm{nm} / \mathrm{min})$

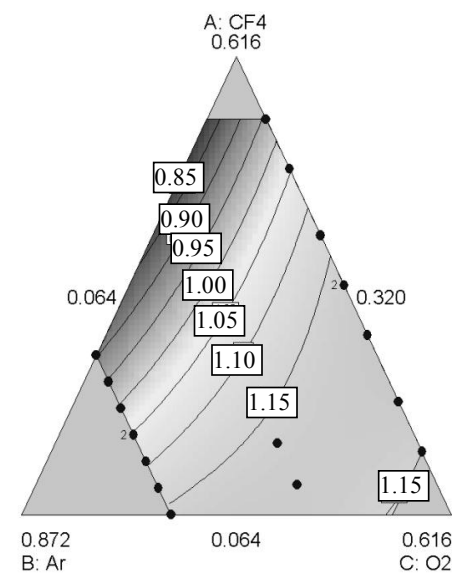

b. Etch selectivity to resist

Figure 2. The etch rate (a) and etch selectivity (b) of BARC1.

To understand polymer behavior in plasma etching, we must understand how polymers decompose in the high-energy reactive particle environment. Plasma etching is a very aggressive decomposition process that includes physical bombardment and chemical reaction. Physical bombardment is the force used to break the polymer bonds and cut the long chains to small pieces. Pieces that are small enough diffuse to the gas phase and are vacuumed out of the chamber; some pieces are redeposited back onto the surface. The scission can occur at backbone, side chain, and hydrogen. Chemical reaction between plasma and polymer, or between polymer segments, may increase the decomposition process or form a more stable structure to slow down the etch process.

For polyacrylate, the scission of the long $\mathrm{C}-\mathrm{C}$ main chain is the major step in breaking down the polymer network. Etching carbon is the slowest step because carbon is a small sputtering yield structure [3]. The free radicals generated from $\mathrm{C}-\mathrm{C}$ chain scissions have a chance to go through $\mathrm{C}=\mathrm{C}$ formation and intermolecularly crosslink, which reduces the effect of bombardment. The most efficient way to etch these types of materials is to use $\mathrm{O}_{2}$ plasma, which breaks the bonds and burns carbon into $\mathrm{CO}_{2}$ gas.

\subsubsection{Nitrogen-containing material}

Not all polymers etch fast in $\mathrm{O}_{2}$ plasma. Figure 3 shows the etch rate and selectivity of BARC2, which contains an isocyanurate compound and is grafted with a chromophore. Unlike the acrylate polymers, the highest etch rate of 
BARC2 in Figure 3a is not at the $\mathrm{O}_{2}$-rich corner of the triangle but is further in the $\mathrm{CF}_{4}$ direction. In other words, the isocyanurate structure is more sensitive to the $\mathrm{CF}_{4}$ gas. Compared to the resist, the selectivity of BARC2 reached 1.35 with the $\mathrm{CF}_{4} / \mathrm{O}_{2}(60 / 40)$ mixing recipe. Although the etch rate of BARC2 is not very high, it has a high selectivity to the resist simply because isocyanurate and polyacrylate respond to the $\mathrm{CF}_{4}$ etch gas differently.

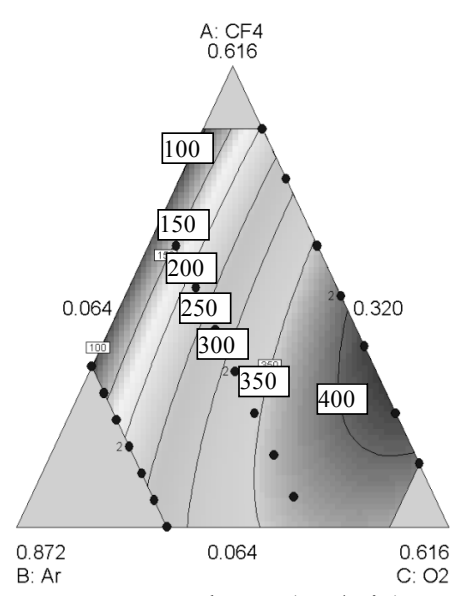

a. Etch rate $(\mathrm{nm} / \mathrm{min})$

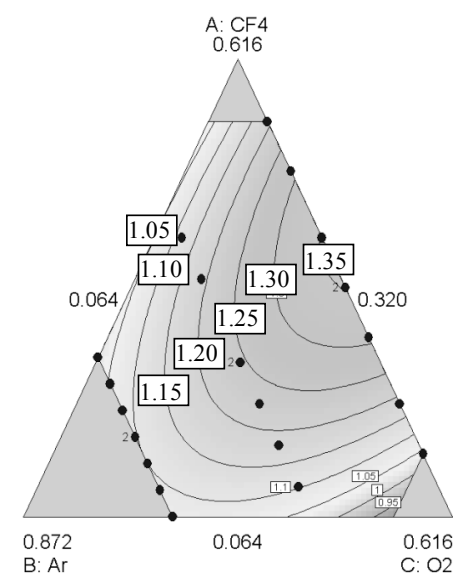

b. Etch selectivity to resist

Figure 3. The etch rate (a) and etch selectivity (b) of BARC2.

Isocyanurate, $-(\mathrm{O}=) \mathrm{C}-\mathrm{N}$, is a unique structure with one-third of its weight percent in its nitrogen and stable $\mathrm{C}-\mathrm{N}$ ring. From our experience, melamine-type materials have an etch behavior similar to that of isocyanurate, which has twothirds of its weight percent in its nitrogen and stable conjugated C-N ring. Combustion theory explains the function of the C-N ring during polymer degradation in air very well. Since both processes are very aggressive polymer decomposition processes, we applied combustion theory to explain polymer decomposition in $\mathrm{O}_{2}$ plasma. In the combustion process, the structure of the $\mathrm{C}-\mathrm{N}$ ring could undergo progressive condensation to form a very stable structure, known as melem, which is incorporated into the combustion residue at a higher efficiency than fused aromatic heterocycles $[13,14]$. If we apply this mechanism to $\mathrm{O}_{2}$ etching, the $\mathrm{C}-\mathrm{N}$ ring trends to form a stable structure, just like a benzene ring. The nitrogen in the $\mathrm{C}-\mathrm{N}$ ring is a slow etch material.

From a high-energy particle perspective, physical bombardment of $\mathrm{O}_{2}$ and $\mathrm{CF}_{4}$ plasma may be similar. But, as reactive species, $\mathrm{O}_{2}$ is an oxidation agent and $\mathrm{CF}_{4}$ is a reducing gas. One important step during $\mathrm{CF}_{4}$ etching is when fluorine replaces hydrogen or substitutes hanging groups. Results of XPS analysis of the surface of polymer film before and after $\mathrm{CF}_{4}$ etching, shown in Table 1, demonstrates this phenomenon. The C-N ring must be broken easily and cannot form a slow-etch structure in a $\mathrm{CF}_{4}$ environment. Nitrogen in the $\mathrm{C}-\mathrm{N}$ ring becomes a fast-etch material during $\mathrm{CF}_{4}$ etching. The remaining part of the material having the regular $\mathrm{C} / \mathrm{H} / \mathrm{O}$ structure still prefers $\mathrm{O}_{2}$ to burn, so the $\mathrm{CF}_{4}$ and $\mathrm{O}_{2}$ mixture is the best etch recipe for achieving the highest etch rate.

Table 1. Surface fluorine content change before and after $\mathrm{CF}_{4}$ etching, analyzed with an XPS. Data are normalized by carbon.

\begin{tabular}{|c|c|c|}
\hline & Before $\mathrm{CF}_{4}$ etch & After $\mathrm{CF}_{4}$ etch \\
\hline $\mathrm{F}$ & 0 & 49.77 \\
\hline $\mathrm{C}$ & 100 & 100 \\
\hline
\end{tabular}

\subsubsection{Polyester}

BARC3 is a polymer containing ester bond and $-(\mathrm{O}=) \mathrm{C}-\mathrm{N}-$ ring in the main chain. The overall etch rate of this material is higher than that of BARC1 and BARC2 because it has fewer aromatic rings functioning as the chromophore. From Figure $4 \mathrm{a}$, we can see the etch rate trend is similar to the etch rate trend of the acrylate resist in Figure 1a, but the selectivity graph, Figure 4b, shows the difference. BARC3 is more sensitive to Ar, and the condition producing the best selectivity is an Ar-rich recipe. This property comes from the ester linkage on the polymer chain. Also, along the $\mathrm{CF}_{4}$ 
and $\mathrm{O}_{2}$ axes, the highest selectivity spot is about midway between $\mathrm{CF}_{4}$ and $\mathrm{O}_{2}$, which is caused by the $-(\mathrm{O}=) \mathrm{C}-\mathrm{N}$ - ring structure and reflects a performance similar to BARC2.

As discussed in 3.1.1, physical bombardment is not an efficient way to etch polyacrylate; oxygen burning is the better method to decompose the polymer. Polyester basically works the same way as polyacrylate does, but it is relatively more sensitive to heavy bombardment of Ar, as shown in Figure 4b. Ester contains more oxygen that can easily sputter away. Also, oxygen can catch free radicals that are generated when the polyester bond $-\mathrm{O}-\mathrm{C}(=\mathrm{O})$ - breaks to prevent double bond formation and intermolecular crosslinking. Compared to polyacrylate, bombardment is more efficient for decomposing the polyester.

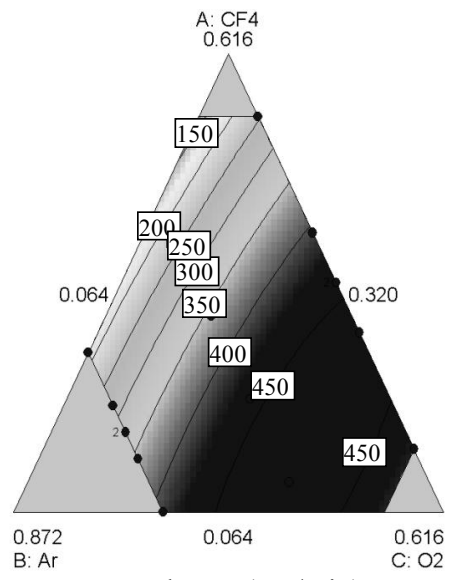

a. Etch rate $(\mathrm{nm} / \mathrm{min})$

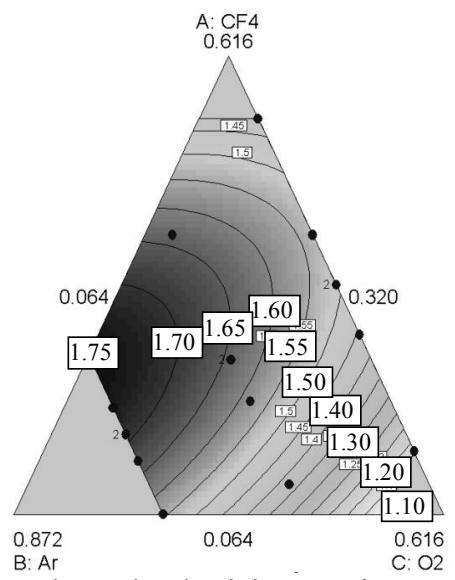

b. Etch selectivity to resist

Figure 4 . The etch rate (a) and etch selectivity (b) of BARC3.

\subsection{Modification of Ohnishi parameter}

With the development of advanced semiconductor technology, the requirements for materials are pushed to be very specific and extreme. More and more new polymers are used in lithography and other areas, and some of these polymers contain elements other than $\mathrm{C}, \mathrm{H}$, and $\mathrm{O}$, such as nitrogen, phosphorous, sulfur, fluorine, bromine, iodine, boron, silicon, and so on. These polymers have received much attention because of the unique functions that they can provide. The Ohnishi parameter is a basic function of polymer structure and plasma etch rate derived from sputtering yield and the composition of $\mathrm{C}, \mathrm{H}$, and $\mathrm{O}$ in a unit volume [3]. Much research has been done to study the etch properties of different new polymers, but no clear theory shows how to put atoms other than $\mathrm{C}, \mathrm{H}$, and $\mathrm{O}$ into the etch equation.

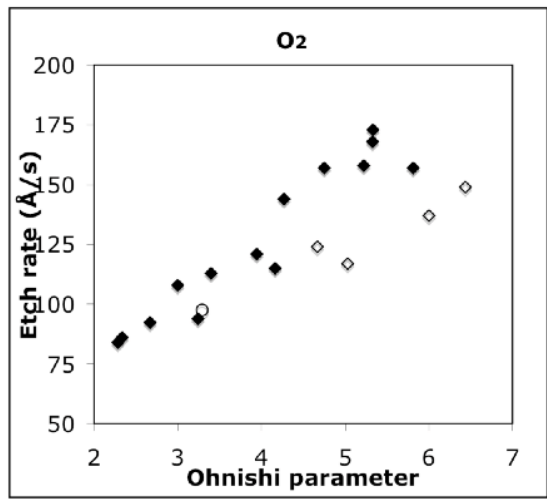

a. $\mathrm{O}_{2}$ etching.

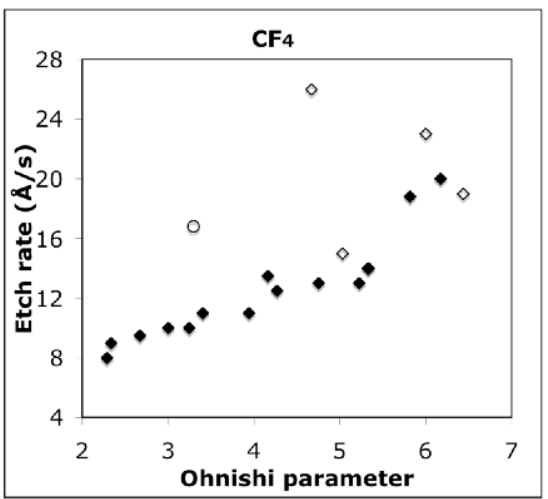

b. $\mathrm{CF}_{4}$ etching.

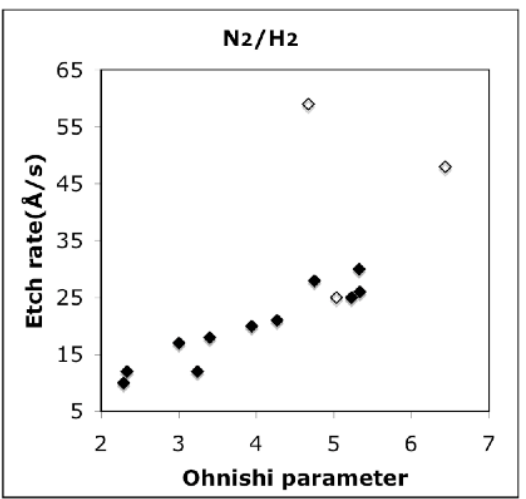

c. $\mathrm{N}_{2} / \mathrm{H}_{2}$ etching.

: Polymers with $\mathrm{C}, \mathrm{H}$, and $\mathrm{O}$ only.

$\diamond:$ Polymers with isocyanate or melamine structure.

O: Polymers with bromine

Figure 5. Etch rate and Ohnishi parameter plots. 
In this study, we tested many polymers with different compositions and structures in three simple recipes: $\mathrm{O}_{2}, \mathrm{CF}_{4}$, and $\mathrm{N}_{2} / \mathrm{H}_{2}$. Figure 5 shows the plots of etch rate versus Ohnishi parameter for each of the polymers. The polymers containing only $\mathrm{C}, \mathrm{H}$, and $\mathrm{O}$ follow the linear trend line nicely, but most of the materials containing isocyanate or melamine or bromide are out of the linear trend line. The etch rates of these materials are below the trend line for $\mathrm{O}_{2}$ etching, and above the trend line in $\mathrm{CF}_{4}$ and $\mathrm{N}_{2} / \mathrm{H}_{2}$ etching. We can see clearly that these structures have a significant effect on plasma etch rate, and the effects of the oxidizing gas and the reducing gas are different.

\subsubsection{Nitrogen in polymer}

The etch gas composition DOE discussed in 3.1.2 and the Ohnishi plots in Figure 5 show that the C-N ring structure etches slower in $\mathrm{O}_{2}$ and faster in $\mathrm{CF}_{4}$ and $\mathrm{N}_{2} / \mathrm{H}_{2}$ than it should. Based on polymer decomposition theory, we know the $\mathrm{C}-\mathrm{N}$ ring can form a stable structure and performs like aromatic carbon ring in $\mathrm{O}_{2}$. In this case, nitrogen has negative contribution to etch, which should be considered as the same function of carbon. The appropriate etch rate equation is:

$$
\text { EtchRate } \propto \frac{N_{\text {total }}}{N_{C}-N_{O}+N_{N}} \quad \text { (In oxidizing gas) }
$$

Where $N_{\text {total }}$ is the total number of atoms, $N_{C}$ is the number of carbon atoms, $N_{O}$ is the number of oxygen atoms, and $N_{N}$ is the number of nitrogen atoms.

However, when the C-N ring is exposed to a reducing gas plasma, such as $\mathrm{CF}_{4}$ and $\mathrm{N}_{2} / \mathrm{H}_{2}$, it degrades easily and does not form a slow-etch structure. In this case, nitrogen is a fast-etch material that makes a positive contribution to etching, and therefore should be treated the same as oxygen in the etch rate equation:

$$
\text { EtchRate } \propto \frac{N_{\text {total }}}{N_{C}-N_{O}-N_{N}} \quad \text { (In reducing gas) }
$$

Then, in Figure 6, we plotted our oxidizing gas parameter and reducing gas parameter with nitrogen factors against etch rate in three etch recipes. All points in each graph were fitted with a linear trend line, each having little variation as indicated by the good $R^{2}$ values.

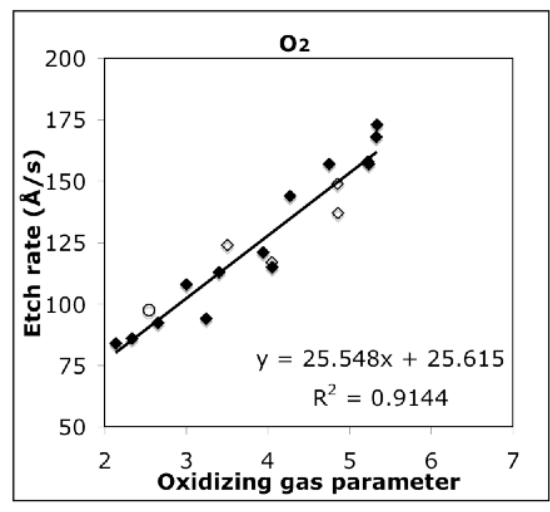

a. $\mathrm{O}_{2}$ etching.

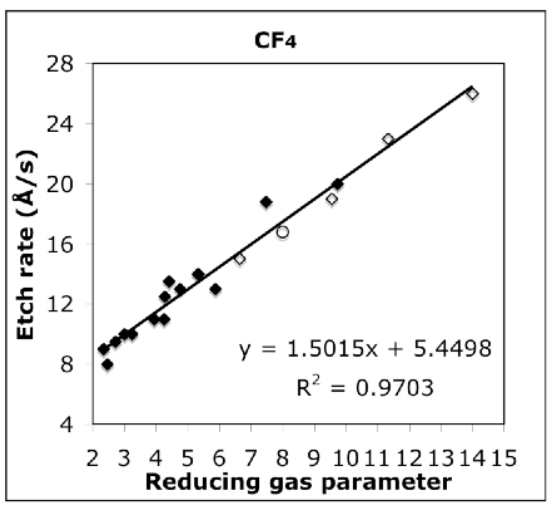

b. $\mathrm{CF}_{4}$ etching.

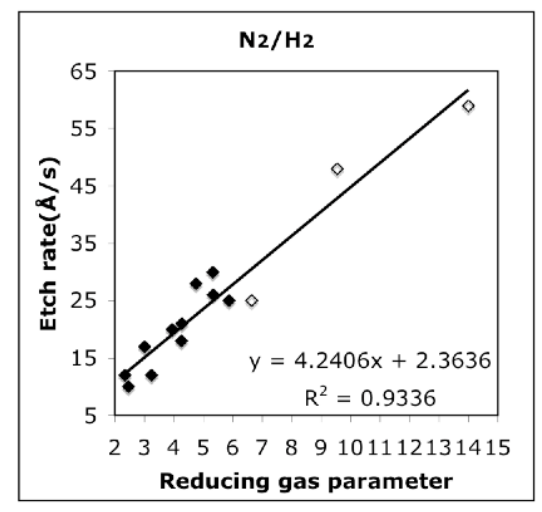

c. $\mathrm{N}_{2} / \mathrm{H}_{2}$ etching.

: Polymers with $\mathrm{C}, \mathrm{H}$, and $\mathrm{O}$ only.

$\diamond:$ Polymers with isocyanate or melamine structure.

O: Polymers with bromine

Figure 6. Etch rate and modified Ohnishi parameter plots.

\subsubsection{Halogen in polymer}

The bromide polymer also showed the difference indicated in Figure $5 \mathrm{a}$ and $5 \mathrm{~b}$, that is, its etch rate is relatively slower in $\mathrm{O}_{2}$ and faster in $\mathrm{CF}_{4}$. The bromine bond is a weak bond in the polymer, which can be easily broken and forms a bromine 
radical. When the bromide polymer combusts in air, the bromine radical immediately abstracts hydrogen from the polymer, and, finally, leaves $\mathrm{C}=\mathrm{C}$, a stable structure, in the polymer. $\mathrm{HBr}$ will quickly react with hydrogen and the hydroxyl radical and regenerate the bromine radical; the process then repeats [13]. The same thing happens in $\mathrm{O}_{2}$ plasma etching, we believe. Therefore, bromine in $\mathrm{O}_{2}$ etching is a slow-etch factor. Depending on the lifetime of the bromine radical, one bromine atom may have the equivalent function of several or less than one carbon atoms. Then the etch rate equation becomes:

$$
\text { EtchRate } \propto \frac{N_{\text {total }}}{N_{C}-N_{O}+n N_{B r}} \quad \text { (In oxidizing gas) }
$$

Where $N_{B r}$ is the number of bromine atoms, and $n$ is the parameter representing the efficiency of the bromine radical. In Figure $6 \mathrm{a}, n=0.5$ was used to fit the data.

In $\mathrm{CF}_{4}$ plasma, bromine radicals cannot start the reaction of abstracting the hydrogen because hydrogen is replaced by fluorine first, as shown in Table 1. With the bigger size and the weaker bond than carbon and oxygen, the sputtering yield of bromine should be high, in other words, bromine is the fast-etch material in $\mathrm{CF}_{4}$ etching. The etch equation becomes:

$$
\text { EtchRate } \propto \frac{N_{\text {total }}}{N_{C}-N_{O}-m N_{B r}} \quad \text { (In reducing gas) }
$$

Where $m$ is the parameter representing the bonding energy and atom size. In Figure $6 \mathrm{~b}, m=4$ was used to fit the data.

Halogen-containing polymers have been used in lithography for a long time, for example, fluorine-containing polymers have been used in photoresists. With the use of shorter exposure light wavelengths for photolithography, aromatic structures cannot be used as a plasma etch mask in a photoresist due to their strong absorbance. Fluorine-containing polymers have been developed because of their etch resistance and transparence. The etch properties of halogenated polymers are not exactly like the polymers that contain only C, H, and O. In his 1983 paper [3], Ohnishi found halogencontaining polymers were not following the trend in certain etch gases. From the literature, we can see that people had modified the Ohnishi parameter to fit their etch rates of fluorine-containing polymers in different ways. However, the modifications are more mathematical, and there is no theory that can explain the physical meaning. Here, we selected three published papers and analyzed their data and conclusions based on our polymer decomposition theory.

The first paper, by Kishimura et al. and published by SPIE in 2002, studied fluorine-containing polymers etched in $\mathrm{Cl}_{2}-$ based plasma. A negative $N_{F}$ was added in the equation (5) to get a better fit for their data [8]. Because $\mathrm{Cl}_{2}$ is a reducing gas, the halogen atoms in the polymer should be the fast-etch material. The number of fluorine atoms, $N_{F}$, in the etch equation should be negative.

$$
\text { EtchRate } \propto \frac{N_{\text {total }}}{N_{C}-N_{O}-N_{F}} \quad \text { (In reducing gas) }
$$

The second paper, by Koh et al. and published by SPIE in 2002, studied the plasma etch properties of fluorinecontaining polymers in $\mathrm{Ar} / \mathrm{C}_{4} \mathrm{~F}_{8} / \mathrm{O}_{2}(400 / 11 / 8)$ etch. A positive $N_{F}$ was added in the equation (6) to fit their data [9]. When more than one gas is in the plasma chamber, many species are generated in the gas phase. The total result could vary depending on the gas ratio and other plasma condition. Although the plasma gas in this paper was a mixture of $\mathrm{C}_{4} \mathrm{~F}_{8} / \mathrm{O}_{2}$ at ratio of $11 / 8$, the plasma in the gas phase is still dominated by $\mathrm{O}_{2}$ plasma. The fluorine in the polymer is a slow-etch material in this oxidizing environment. The number of fluorine atoms in the etch equation should be positive.

$$
\text { EtchRate } \propto \frac{N_{\text {total }}}{N_{C}-N_{O}+k N_{F}{ }^{n}} \quad \text { (In oxidizing gas) }
$$

The third paper, by Patel et al. and published by SPIE in 2006, studied the plasma etch properties of fluorine-containing polymers in $\mathrm{CF}_{4}$-based plasma. A negative $N_{F}$ was added in the equation (7) to fit their data [7]. Fluorine in the polymer is the fast-etch material in the reducing gas $\mathrm{CF}_{4}$. The number of fluorine atoms in the etch equation should be negative. 


$$
\text { EtchRate } \propto \frac{N_{\text {total }}}{N_{C}-0.87 N_{O}-0.41 N_{F}} \quad \text { (In reducing gas) }
$$

A halogen in oxidizing gas functions as a radical transfer agent. Different parameters could be used for the halogen factor in the etch equation depending on the efficiency and the lifetime of halogen radicals. The bonding energy and atom size of different halogen atoms could affect parameters in a reducing gas etch equation. Bromine has weak bond and large size, so we used $\mathrm{m}=4$ in our experiment. Fluorine is small and forms stronger bonds, so Patel et al., 2006, found that $m=0.41$ fits best.

\subsection{Bonding contribution in plasma etch}

The bond contribution model, by Yu et al. and published by SPIE 2001, fitted experimental data by bond types, which gave single bonds and double bonds different parameters in the equation (8) [5].

$$
\text { BondContributionModel }=N_{C-C} \times C_{1}+N_{C=C} \times C_{2}+N_{C-O} \times C_{3}+N_{C=O} \times C_{4}+N_{O-H} \times C_{5}+N_{C-H} \times C_{6}+C_{0}
$$

Where $N$ is the number of bond in polymer, $C$ is the parameter of the contribution.

However, if we consider one atom is shared by the bonds surrounding it, the carbon in C-C is shared by four bonds, which is considered as one-fourth of carbon; the carbon in $\mathrm{C}=\mathrm{C}$ is shared by three bonds, which is considered as onethird of carbon, the oxygen in $\mathrm{C}-\mathrm{O}$ is shared by two bonds which is considered as one half of oxygen. Also, assuming that the carbon contribution to etch is negative and the oxygen and hydrogen contribution to etch is positive, we can get the same parameter for $\mathrm{C}-\mathrm{C}$ and $\mathrm{C}=\mathrm{C}, \mathrm{C}-\mathrm{O}$ and $\mathrm{C}=\mathrm{O}$, as well as the absolute value of $\mathrm{C}-\mathrm{H}$ and $\mathrm{O}-\mathrm{H}$. The calculation details are listed in Table 2 .

Table 2. Comparison of bonding contribution and atom contribution

\begin{tabular}{|c|c|c|c|c|}
\hline Bond & $\begin{array}{l}\text { Parameter } \\
\text { in Eq. (8) }\end{array}$ & $\begin{array}{l}\text { Parameter } \\
\text { in Eq. }(8)\end{array}$ & \multicolumn{1}{|c|}{ Atom contribution } & $\begin{array}{l}\text { Parameter in Eq. (8) / } \\
\text { Atom contribution }\end{array}$ \\
\hline $\mathrm{C}-\mathrm{C}$ & $\mathrm{C}_{1}$ & -0.13 & $(-1 / 4)+(-1 / 4)=(-1 / 2)$ & 0.260 \\
\hline $\mathrm{C}=\mathrm{C}$ & $\mathrm{C}_{2}$ & -0.17 & $(-1 / 3)+(-1 / 3)=(-2 / 3)$ & 0.254 \\
\hline $\mathrm{C}-\mathrm{O}$ & $\mathrm{C}_{3}$ & 0.13 & $(-1 / 4)+(+1 / 2)=(+1 / 4)$ & 0.520 \\
\hline $\mathrm{C}=\mathrm{O}$ & $\mathrm{C}_{4}$ & 0.4 & $(-1 / 3)+(+1)=(+2 / 3)$ & 0.597 \\
\hline $\mathrm{O}-\mathrm{H}$ & $\mathrm{C}_{5}$ & -0.07 & $(+1 / 2)+(+1)=(+3 / 2)$ & -0.047 \\
\hline $\mathrm{C}-\mathrm{H}$ & $\mathrm{C}_{6}$ & 0.04 & $(-1 / 4)+(+1)=(-3 / 4)$ & 0.053 \\
\hline
\end{tabular}

Bonding contribution is less important than atom contribution in this process. The plasma energy is much higher than bonding energy, which can break all kinds of bonds without difference. The sputter yield related to the atom property and reaction with plasma gas are the basic factors to determine the etch rate.

\section{CONCLUSION}

Plasma etching of polymeric materials is a decomposition process. The basic decomposition mechanisms for polymers, such as chain secession, free radical formation, the reaction to environmental gas, still apply on plasma etching well. For most polymers, $\mathrm{O}_{2}$ is the most efficient gas to burn carbon, but not all materials etch fast in $\mathrm{O}_{2}$. The $\mathrm{C}-\mathrm{N}$ ring is involved in forming a slow-etch structure during $\mathrm{O}_{2}$ etching, and is easy to break in a reducing gas, which gives the materials with the C-N ring structure high selectivity to other polymers during etching in a reducing gas. A halogen in a polymer can generate more double bonds and crosslink to reduce the etch rate in $\mathrm{O}_{2}$ gas, but this reaction cannot happen in a reducing gas, which makes halogenated materials etch fast in a reducing gas. Oxygen in the polymer backbone is a free radical inhibiter that enhances the bombardment effect by stopping the formation of new $\mathrm{C}=\mathrm{C}$ and crosslinking. A polymer with oxygen in its backbone usually has high selectivity in heavy atom Ar plasma. Depending on the function of atoms in the oxidizing gas or reducing gas plasma, nitrogen and halogen were added in the etch equations as positive or negative factors. Using these equations, we were able to get a nice fit for all materials in different etch conditions. 


\section{REFERENCES}

1. Armacost, M., Hoh, P. D., Wise, R., Yan, W., Brown, J. J., Keller, J. H., Kaplita, G., A., Halle, S. D., Muler, K. P., Naeem, M. D., Srinvesan, S., Ng, H. Y., Gutsche, M., Gutmann, A., Spuler, B., "Plasma-etching processes for ULSI semiconductor circuits," IBM Journal of Research and Development, vol. 43, 39-72 (1999).

2. Oehriein, G. S., Doeming, M. F., Matsuo, P. J., Rueger, N. R., Schaepkens, M., Standaert, T. E. F. M., "Surface science issues in plasma etching," IBM Journal of Research and Development, vol. 43, 181-197 (1999).

3. Gokan, H., Esho, S., and Ohnishi, Y., "Dry etch resistance of organic materials," Journal of the Electrochemical Society, vol. 130, 143-146 (1983).

4. Kunz, R., Palmteer, S., Forte, A., Allen, R., Wallraff, G., DiPietro, R., Hofer, D., "Limits to etch resistance for 193nm single-layer resists," Proceedings of SPIE, vol. 2724, 365 (1995).

5. Yu, T., Ching, P., Ober, C., Hall, B., Deshpande, S., Puligadda, R., "Development of a bond contribution model for structure: property correlation in dry etch studies," Proceedings of SPIE, vol. 4345, 945-951 (2001).

6. Perret, D., Andes, C. E., Cheon, K. S., Sobhian, M., Szmanda, C. R., Barclay, G. G., Trefonas, P., "Etch resistance: comparison and development of etch rate models," Proceedings of SPIE, vol. 6519, 651912-1 - 651912-12 (2007).

7. Patel, K. S., Pham, V., Li, W., Khojasteh, M., Varanasi, P. R., "Reactive ion etching of fluorine containing photoresist," Proceedings of SPIE, vol. 6153, 61530Q-1 - 61530Q-10, (2006).

8. Kishimura, S., Endo, M. Sasago, M., "New 157-nm resist platforms based on etching model for fluoropolymers," Proceedings of SPIE, vol. 4690, 200-211 (2002).

9. Koh, M., Ishikawa, T. Araki, T., Aoyama, H., Yamashita, T., Yamazaki, T., Watanabe, H., Totiumi, M., Itani, T., "Dry etch resistance of fluorine functionalized polymers," Proceedings of SPIE, vol. 4690, 486-496 (2002).

10. Ling, L., Hua, X., Oehrlein, G.S., Hudson, E. A., Lazzeri, P., Anderle, M., "Investigation of surface modifications of 193 and $248 \mathrm{~nm}$ photoresist materials during low-pressure plasma etching," Journal of Vacuum Science and Technology, B 22(6), Nov/Dec, 2594-2630 (2004).

11. Standaet, T. E. F. M., Matsuo, P. J., Li, X., Oehrlein, G. S., Lu, T. M., Gutmann, R., Rosenmayer, C. T., Bartz, W. J., Langan, J. G. , Entley, W. R., "High-density plasma patterning of low dielectric constant polymers: a comparison between polytetrafluoroethlene, parylene-N, and poly(arylene ether)," Journal of Vacuum Science and Technology, A 19(2), Mar/Apr, 435-446 (2001).

12. Bazin, A., May, M., Pargon, E. Mortini, B., Joubert, O., "Study of $193 \mathrm{~nm}$ resist degradation under various etch chemistries," Proceedings of SPIE, vol. 6519, 65192N-1 - 65192N-9 (2007).

13. Levchik, S. V., Flame retardant polymer nanocomposites, Wiley \& Son, Inc., Chapter 1, "Introduction to flame retardance and polymer flammability," 1-29 (2007).

14. Ramirez, M. L., Walters, R., Savitski, E. P., Lyon, R. E., “Thermal decomposition of cyanate ester resins," U.S. Department of Transportation Report No. DOT/FAA/AR-01/32, National Technical Information Service, Springfield, Virginia, (2001). 